\title{
Modern contraceptive use among unmarried girls aged 15-19 years in South Western Nigeria: results from a cross-sectional baseline survey for the Adolescent 360 (A360) impact evaluation
}

Emily E. Crawford ${ }^{1 *}$ (D), Christina J. Atchison ${ }^{2}$, Yewande P. Ajayi ${ }^{1}$ and Aoife M. Doyle ${ }^{3}$

\begin{abstract}
Purpose: Adolescents 360 (A360) is an initiative being rolled out across Nigeria with the aim of increasing voluntary modern contraception use among women aged 15 to 19 years. Using evaluation study baseline data, we identified sexuality, fertility and contraceptive use characteristics of young unmarried girls in South Western Nigeria.

Methods: A cross-sectional baseline survey of unmarried girls aged 15 to 19 years was conducted in Ogun state, Nigeria in August 2017. A clustered sampling design was used. We identified determinants of modern contraceptive use in this subpopulation using logistic regression.

Results: Of 12,024 women interviewed, 15.3\% reported sexual intercourse in the past year. The majority of respondents $(79.6 \%, 9525 / 11,967)$ had heard of contraception. $45.3 \%$ of sexually active respondents were using a modern contraceptive method. Of those using any method of contraception, male condoms (50.3\%) were the most widely used modern method followed by the emergency contraceptive pill (16.7\%). Following adjustment for sociodemographic characteristics, there was evidence that the use of modern contraception was positively associated with having never given birth, living in an urban area, current enrolment in education, high level of education, high socioeconomic status, exposure to information about contraception, perceived social support for contraception, and self-efficacy for contraception.
\end{abstract}

Conclusions: In South Western Nigeria, unmarried sexually active adolescent girls have relatively low levels of modern contraceptive use. Programmes should aim to increase access to modern contraception and to increase social support and acceptability of contraceptive use.

Keywords: Adolescent health, Reproductive health, Modern contraception, Nigeria, Sub-Saharan Africa, Impact evaluation

\section{Plain English summary}

Purpose: Many sexually active young women who do not want to get pregnant are not using modern contraception to prevent pregnancy. Adolescents 360 (A360) hopes to

*Correspondence: emmyloo@gmail.com

1 Binomial Optimus Limited, Blue Hill, PLOT 538 Natasha Akpoti Street Kado, Abuja, FCT, Nigeria

Full list of author information is available at the end of the article help young Nigerian women prevent pregnancy if they want to. This paper explains which young women in South West Nigeria are more likely to use modern contraception than others.

Methods: We interviewed unmarried girls 15-19 years old in Ogun State, Nigeria. We asked them about their sexual activity and attitudes towards contraception.

Results: We interviewed 12,053 women. 15.3\% said they had sex in the past year. Most women had heard of original author(s) and the source, provide a link to the Creative Commons licence, and indicate if changes were made. The images or other third party material in this article are included in the article's Creative Commons licence, unless indicated otherwise in a credit line to the material. If material is not included in the article's Creative Commons licence and your intended use is not permitted by statutory regulation or exceeds the permitted use, you will need to obtain permission directly from the copyright holder. To view a copy of this licence, visit http://creativecommons.org/licenses/by/4.0/. The Creative Commons Public Domain Dedication waiver (http://creativeco mmons.org/publicdomain/zero/1.0/) applies to the data made available in this article, unless otherwise stated in a credit line to the data. 
contraception. Even though they had heard about modern contraception, they did not know any place where they would feel comfortable getting it. Less than half of the women who had sex were using modern contraception. Among the women who were using modern contraception, half $(50 \%)$ were using male condoms followed by the emergency contraceptive pill (17\%). Women were more likely to use modern contraception if they had never given birth before, lived in a city, had spent more time in school, were in school now, had heard about contraception, felt their family and friends supported them in using contraception, and felt able to get contraception.

Conclusions: Programs wanting to help young unmarried girls in Nigeria to prevent pregnancy should make available safe places where they can get contraception. These programs should also work with friends and families of girls to help these women feel more supported to get contraception.

\section{Introduction}

Despite increases in both knowledge about modern contraception (MC) and desire to delay or space child births, many sub-Saharan African (SSA) women still have low uptake of modern contraceptives and high rates of unmet need [1,2]. Closing this gap is a global priority currently being addressed through the Family planning 2020 (FP2020) initiative and United Nation's Sustainable Development Goals (SDG) 3 and 5 focusing on health and well-being for all and gender equality $[3,4]$. The gap in access to MC is particularly pronounced for girls in LMICs as compared to high-income countries; for instance, $22 \%$ of girls aged 15-19 years in Nigeria report using a MC at the last time they had sexual intercourse, compared with more than half in the UK and 39\% in the USA [5-7]. Low MC uptake contributes to high adolescent pregnancy rates, and poor health outcomes including maternal morbidity and mortality, and neonatal and under-five child mortality [1, 8, 9]. In addition, unplanned pregnancy can lead to other severe social and economic consequences for girls, their families, and society as a whole, including not reaching their potential for educational achievement, and not getting a paid job, often leading into a cycle of poverty $[8,10]$.

Most studies to date have focused on the factors associated with use of MC by women of reproductive age (15-49 years) [1], with adolescents (15-19 years) usually underrepresented [8]. Most literature on access to MC has focused on married women, though unmet demand for and access to MC among adolescents are known to differ with women's marital status, with unmet need for MC highest among unmarried girls [11, 12]. For the goals of FP2020 and SDG 3 and 5 to be achieved, more information is needed on factors associated with contraceptive use among unmarried girls in low contraceptive prevalence settings such as Nigeria.

While studies on contraceptive use among adolescents in Africa are scarce, studies on determinants of adolescent pregnancy can shed light on factors that may be associated with contraceptive use. Systematic reviews have shown poverty, education, parental involvement, access to education on contraceptives, and misconceptions about contraception to be associated with adolescent pregnancy in African countries [13, 14]. Nigerian adolescents face unique barriers in obtaining knowledge of and access to contraception. Although Nigeria adopted a curriculum for Family Life and HIV Education in 2003; this curriculum mentions safer sex in the context of HIV prevention, but omits any reference to contraception [15-17]. Access to contraception can be more challenging for adolescents; while age of consent for sexual activity in Nigeria is 18 [18], access to contraceptives is not officially restricted based on age [19]. Many providers, however, restrict access to contraception based on age or parity restrictions of their own; this is likely an act of selfpreservation in the face of unclear laws [20].

Adolescents 360 (A360) is an initiative being rolled out across Ethiopia, Nigeria and Tanzania to increase voluntary uptake of MC among sexually active women aged $15-19$ years [21]. A360 is country-adapted, and in Southern Nigeria combines community advocacy alongside safe spaces for girls to learn about contraception and to access MC methods [21]. Funding for A360 comes from the Bill and Melinda Gates Foundation and the Children's Investment Fund Foundation.

Using baseline survey data collected as part of the A360 programme evaluation, we describe sociodemographic characteristics, sexual activity, and contraceptive use of unmarried girls aged 15-19 years in Ogun State, South Western Nigeria, and determined factors associated with $\mathrm{MC}$ use among unmarried sexually active girls.

\section{Methods}

Between August and October 2017, we conducted a cross-sectional household survey among unmarried girls aged 15-19 years in Shagamu and Ado-Odo Ota local government areas (LGA) in Ogun State, South Western Nigeria. These LGA were selected based on planned implementation of the A360 Initiative in Ado-Odo Ota, with Shagamu selected as a comparison. Ogun State has an estimated total population of 5.8 million [22], and shares its Southern border with Lagos state. Overall, $36 \%$ of the female household population has no education, and the median age at first marriage for women is 19.1 years [7]. 
Full details of the sampling strategy and sample size calculations are described elsewhere [21].

Girls were included if they were 15-19 years old, unmarried, and living in the study sites at the time of the survey. Respondents were classified as unmarried if they reported that they did not have a husband or were not living as married with a cohabiting male partner.

A cluster sampling design was used. The primary sampling unit was the 2006 census enumeration area (EA), parent/guardian. The study protocol was approved by the National Health Research Ethics Committee of Nigeria (Ref: NHREC/01/01/2007-25/05/2017) and the London School of Hygiene and Tropical Medicine Ethics Committee (Ref: 14145).

\section{Study outcome}

The Modern Contraceptive Prevalence Rate (mCPR) among unmarried-sexually active girls aged $15-19$ years was defined as follows:

$$
m C P R=\frac{\begin{array}{c}
\text { Number of unmarried sexually active } * \text { girls aged } 15-19 \text { years reporting } \\
\text { use of modern contraceptives at the time of the survey }
\end{array}}{\text { Number of unmarried sexually active } * \text { girls aged } 15-19 \text { years }}
$$

the smallest administrative unit of Nigeria. All eligible consenting unmarried girls aged 15-19 years residing in households in these EAs were invited to be interviewed [21]. If potentially eligible participants were not available, two revisits were made to attempt to hold interviews. At the 2006 census, each EA was defined to have approximately 100 households, however, the number of households per EA in 2017 was likely to vary. We took a simple random sample of EAs across the two LGAs and, to maximise the efficiency of the survey logistics, sampled clusters of approximately 100 households in or near the sampled EAs. Thus, if an EA contained fewer than 100 households, we randomly sampled a neighbouring EAs and enumerated all households in that EA as well. If an EA exceeded 150 households, we divided the EA into approximately equal sections of 75-100 households and randomly selected one section for enumeration. A simple random sample of 716 EAs was needed to reach the target sample size of 12,000 women.

The questionnaire was adapted from research instruments used in the Nigeria Demographic and Health Survey (DHS) [23] and FP2020 survey [3]. Questionnaires were administered face-to-face by female interviewers aged between 18 and 26 years using pre-programmed tablet computers [21]. Interviews were conducted in a private location in the respondent's homes in August and September 2017. The questionnaire had three components: (1) sociodemographic characteristics (2) fertility characteristics and preferences, and (3) contraceptive knowledge, attitudes and practices.

Only respondents who reported sexual intercourse in the last 12 months were considered sexually active hence asked questions about contraceptive use [21].

Participants voluntarily provided verbal informed consent. A waiver of written consent was granted given the sensitive nature of the topics discussed. Women aged 15-17 years provided verbal assent and verbal informed consent was also sought from her
"Self-reported that they were sexually active in the 12 months prior to the survey.

Modern contraception was defined to include the following: male and female sterilisation, contraceptive implants, intrauterine contraceptive devices, injectables, contraceptive pill/oral contraceptives, emergency contraceptive pill, male condom, female condom, standard days method (SDM), lactational amenorrhoea method, diaphragm, spermicides, foams and jelly [24].

\section{Statistical analysis}

Data analysis was conducted in Stata V.15.

We used robust SEs to account for the clustered sampling design. We described socio-demographic characteristics, sexual activity, and contraceptive use of unmarried girls. Logistic regression was performed for the subpopulation of sexually active girls. We obtained odds ratios (ORs) for the association of each explanatory variable with use of MC. Wald tests adjusted for the clustered sampling design were used at each step of the analysis. Variables with p-value of $<0.2$ in bivariate analysis were included in multivariable regression models. The association between $\mathrm{mCPR}$ and age was not adjusted for other explanatory variables. The associations between $\mathrm{mCPR}$ and other sociodemographic variables were adjusted for age, an a priori potential confounder. For the remaining explanatory variables, models were adjusted for age and sociodemographic factors which had age-adjusted p-values of $<0.2$. Variables with $p$ value $<0.05$ in the adjusted analysis were considered to have some evidence of an association with $\mathrm{mCPR}$. This strategy allowed us to assess the effect of variables adjusted for distal a priori potential confounders.

Socioeconomic position was created from a series of questions about household items, dwelling materials and access to a bank account using the 'Nigeria Equity Tool'. This tool uses different weights attached to each answer to create a composite score which was then split into 
quintiles according to the national thresholds [25]. Variables for contraception knowledge, holding misconceptions and self-efficacy were created as scores from 0 to 5 for knowledge, and 0 to 4 for holding misconceptions and self-efficacy based on the overall score for each individual statement in each category. A score of 1 was given if the respondent agreed with the statement and 0 if she disagreed or answered 'don't know'. A maximum score of 5 for knowledge and 4 for self-efficacy would indicate that the respondent correctly agreed with all five knowledge statements and felt able to achieve all four self-efficacy behaviours. A maximum score of 4 for holding misconceptions would be interpreted as believing all four myth statements about contraception. As per DHS definition, this study considered three outcomes for unmet need for MC: total unmet need, unmet need for spacing, and for limiting [7]. The total unmet need was the sum of unmet need for spacing and limiting.

\section{Results}

In total 13,481 potentially eligible unmarried girls (1519 years) were identified with 12,053 interviewed and 12,024 (89.2\%) interviewed and responding to sexual history questions. 1428 girls (10.5\%) were identified in the household listing but not reachable or available to be interviewed.

\section{Sexual activity among respondents}

Overall, 15.3\% (1844/12,024) of adolescent women had been sexually active during the 12 months preceding the survey. The median age was 18 years (IQR 18-19) for sexually active and 17 years (IQR $15-18$ ) for non-sexually active women (Table 1). The highest level of education achieved by the majority of respondents was secondary level education. Only $30.5 \%$ of sexually-active adolescent women were currently in education compared to $62.2 \%$ of non-sexually active women (Table 1 ).

The majority of respondents (sexually active: $90.7 \%$, non-sexually active: $77.6 \%$; $<0.001$ ) had heard of contraception. Sexually-active respondents were more likely to have good knowledge (score 4-5) about contraception than non-sexually active respondents $(76.3 \%$ vs. $66.0 \%$; $\mathrm{p}<0.001$ ). A similar proportion held two or more misconceptions (score $\geq 2$ ) about contraception (sexually-active: $68.4 \%$, non-sexually active: 66.4\%; p 0.06 ) (Table 1 ). Over half of sexually active adolescent women felt supported by their partners and friends to use contraception, compared to only about a quarter who felt that they had their mother's support. In addition, only $40.5 \%$ of sexually active women knew of a place where or a person from whom they would feel comfortable accessing contraception. In total, $45.6 \%$ had the maximum self-efficacy score of 4 , with similar proportions (55-59\%) responding positively to each of the individual self-efficacy statements.

The majority of adolescent women reporting no sexual activity within the last 12 months had never had sexual intercourse and $11.8 \%$ reported sexual activity more than a year ago. Of note, the median age of first sexual activity in these women was lower than those reporting sexual activity within the last 12 months (age: 16 years vs. 17 years). About a quarter of sexually active women had been pregnant and 1 in 10 had given birth. Excluding women who were currently pregnant, half of those who reported having ever been pregnant also reported never having given birth (276/553 (49.9\%)).

Unmet need for MC was $29.0 \%$, made up almost entirely of unmet need for spacing (Table 1).

\section{Contraceptive use among sexually active respondents}

Overall, 63.2\% (1165/1844) of unmarried sexually active respondents were using any contraceptive method, with $45.3 \%(836 / 1844)$ using a modern method, and $17.8 \%$ (329/1844) using traditional contraceptive methods (Table 2). Male condoms were the most widely used modern method, used by $50.3 \%(586 / 1165)$ of those using any method. The emergency contraceptive pill was the next most popular modern method, used by $16.7 \%$ $(194 / 1165)$ of contraceptive users. Traditional methods of contraception were commonly used with $20.7 \%$ (241/1165) of contraceptive users reporting use of the withdrawal method.

\section{Characteristics associated with use of MC}

Among sexually active adolescent women, older age, higher level of educational attainment, being currently enrolled in school, living in an urban area, and higher socioeconomic position were all positively associated with use of MC methods (p-value < 0.05) (Table 3). After adjusting for sociodemographic variables, the odds of using $\mathrm{MC}$ were significantly lower for women who had not heard about contraception in the last 12 months in the media (adjOR $0.65,95 \%$ CI $0.51-0.82$ ) or from a health sector source (adjOR 0.53, 95\% CI 0.42-0.68) compared with those that had heard this information. Those who did not know of a place or person from whom they would feel comfortable accessing contraception had lower odds of using MC compared with those who did (adjOR 0.65, 95\% CI 0.53-0.81). The odds of using MC were lower for women who perceived that their partners did not support their use of contraception (adjOR 0.27, 95\% CI $0.20-0.35$ ) and for those who perceived lack of support from their friends (adjOR 0.54, 95\% CI 0.420.70) compared with those who perceived such support. The odds of using MC increased with higher self-efficacy for contraception (score of 4 vs. score of 0-1; adjOR 3.1, 
Table 1 Characteristics of unmarried sexually active and non-sexually active women aged 15-19 years in Ogun, South Western Nigeria ${ }^{a}$

\begin{tabular}{|c|c|c|c|}
\hline \multirow{2}{*}{$\begin{array}{l}\text { Characteristic } \\
\text { Sociodemographic factors }\end{array}$} & \multirow{2}{*}{$\begin{array}{l}\text { Sexually active, } N=1844 \\
n(\%)^{a}\end{array}$} & \multirow{2}{*}{$\begin{array}{l}\text { Non-sexually active, } \\
N=10,180 \\
n(\%)^{a}\end{array}$} & \multirow[t]{2}{*}{$p$ value $^{b}$} \\
\hline & & & \\
\hline \multicolumn{4}{|l|}{ Age (years) } \\
\hline 15 & $66(3.6)$ & $3213(31.6)$ & \\
\hline 16 & $119(6.5)$ & $1854(18.2)$ & \\
\hline 17 & $233(12.6)$ & $1692(16.6)$ & \\
\hline 18 & $552(29.9)$ & $2006(19.7)$ & \\
\hline 19 & $874(47.4)$ & 1415 (13.9) & $<0.001$ \\
\hline Age $\left(\right.$ years) ${ }^{c}$ & $18(18-19)$ & $17(15-18)$ & \\
\hline \multicolumn{4}{|l|}{ Religion } \\
\hline Catholic & $36(2.0)$ & $245(2.4)$ & \\
\hline Protestant/other christian & $1181(64.1)$ & $6195(60.9)$ & \\
\hline Muslim & $620(33.6)$ & $3703(36.4)$ & \\
\hline Traditional & $7(0.38)$ & $31(0.30)$ & \\
\hline No religion & 0 & $1(0.01)$ & \\
\hline Other & 0 & $3(0.03)$ & 0.15 \\
\hline \multicolumn{4}{|c|}{ Highest education level achieved } \\
\hline No education & $21(1.1)$ & $125(1.2)$ & \\
\hline Quranic only ${ }^{\mathrm{d}}$ & 0 & $4(0.04)$ & \\
\hline Primary & $109(5.9)$ & $363(3.6)$ & \\
\hline Secondary & $1547(83.9)$ & 9301 (91.4) & \\
\hline Higher education & $167(9.1)$ & $386(3.8)$ & $<0.001$ \\
\hline \multicolumn{4}{|l|}{ Currently in education } \\
\hline Yes & $563(30.5)$ & $6328(62.2)$ & \\
\hline No & $1281(69.5)$ & $3847(37.8)$ & $<0.001$ \\
\hline \multicolumn{4}{|l|}{ Type of residence } \\
\hline Urban & $662(35.9)$ & $3621(35.6)$ & \\
\hline Semi-urban & $756(41.0)$ & $4257(41.8)$ & \\
\hline Rural & $426(23.1)$ & $2302(22.6)$ & 0.87 \\
\hline \multicolumn{4}{|l|}{ Socioeconomic level } \\
\hline Lowest quintile & $6(0.33)$ & $15(0.15)$ & \\
\hline Second lowest quintile & $6(0.33)$ & $44(0.44)$ & \\
\hline Middle quintile & $62(3.4)$ & $213(2.1)$ & \\
\hline Second highest quintile & $355(19.7)$ & $1587(16.0)$ & \\
\hline Highest quintile & $1376(76.2)$ & $8060(81.3)$ & $<0.001$ \\
\hline \multicolumn{4}{|c|}{ Exposure to information about contraception } \\
\hline \multicolumn{4}{|c|}{ Ever heard about contraception } \\
\hline Yes & $1664(90.7)$ & $7861(77.6)$ & \\
\hline No & $171(9.3)$ & $2271(22.4)$ & $<0.001$ \\
\hline \multicolumn{4}{|c|}{ Heard about contraception in the media in last 12 months? } \\
\hline Yes & $398(23.9)$ & $2177(27.7)$ & \\
\hline No & $1266(76.1)$ & $5684(72.3)$ & 0.002 \\
\hline \multicolumn{4}{|c|}{ Heard about contraception from health sector sources in last 12 months? } \\
\hline Yes & $414(24.9)$ & $1103(14.0)$ & \\
\hline No & $1250(75.1)$ & $6758(86.0)$ & $<0.001$ \\
\hline \multicolumn{4}{|c|}{ Heard about contraception from interpersonal sources in last 12 months? } \\
\hline Yes & $986(59.3)$ & $3941(50.1)$ & \\
\hline No & $678(40.8)$ & $3920(49.9)$ & $<0.001$ \\
\hline
\end{tabular}


Table 1 (continued)

\begin{tabular}{lll}
\hline Characteristic & Sexually active, $N=1844$ & $\begin{array}{l}\text { Non-sexually active, } \\
N=10,180\end{array}$ \\
Sociodemographic factors & $n(\%)^{a}$ & $n(\%)^{a}$ \\
\hline
\end{tabular}

Knows a place where or a person from whom she would feel comfortable accessing contraception?

$\begin{array}{ll}\text { Yes } & 672(40.5) \\ \text { No } & 923(55.7) \\ \text { Don't know } & 63(3.8) \\ \text { Social networks } & \\ \text { Perception that partner supports her using contraceptione } & \\ \text { Yes } & 1058(65.0) \\ \text { No } & 354(21.7) \\ \text { Don't know } & 216(13.3) \\ \text { Perception that mother supports her using contraceptione } & \\ \text { Yes } & 383(25.7) \\ \text { No } & 747(50.2) \\ \text { Don't know } & 359(24.1) \\ \text { Perception that friends supports her using contraception } & \\ \text { Yes } & 925(55.6) \\ \text { No } & 367(22.1) \\ \text { Don't know } & 372(22.4)\end{array}$

Individual knowledge, attitudes and behaviours

Knowledge about contraception ${ }^{f}$

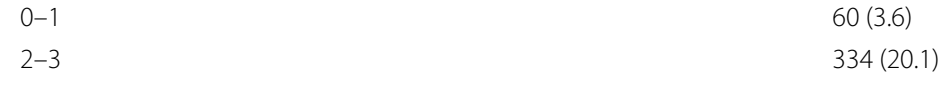

0-1

2-3

4

Self-efficacy for contraception ${ }^{\mathrm{e}, \mathrm{h}}$

$0-1$

2-3

4

745 (45.6)

Timing of most recent sexual activity

Within past week

$302(16.4)$

0

Within past month

$582(31.6)$

$960(52.1)$

0

Within past year

More than 1 year ago

0

Never

Age at first sexual intercourse

$<15$

$15-17$

18-19

Ever been pregnant

Yes, currently pregnant

$98(20.3)$

0

Yes, currently not pregnant

$379(78.5)$

$166(98.8)$

Yes, not sure if currently pregnant

$6(1.2)$

$2(2.2)$

No

$1358(73.6)$

$10,009(98.3)$

Don't know

$3(0.16)$

$3(0.03)$ 
Table 1 (continued)

\begin{tabular}{lll}
\hline Characteristic & Sexually active, $\mathbf{N}=\mathbf{1 8 4 4}$ & $\begin{array}{l}\text { Non-sexually active, } \\
\mathbf{N}=\mathbf{1 0 , 1 8 0} \\
\mathbf{n}(\%)^{\mathbf{a}}\end{array}$ \\
Sociodemographic factors & $\mathbf{n}(\%)^{\mathbf{a}}$ & $\mathbf{p}$ value \\
\hline Ever given birth & $178(9.7)$ & $99(0.97)$ \\
Yes & $1666(90.4)$ & $10,081(99.0)$ \\
No & & \\
Unmet need for modern contraception ${ }^{e, i}$ & $1223(71.0)$ & \\
No unmet need & $496(28.8)$ & \\
Unmet need for spacing & $3(0.17)$ & \\
Unmet need for limiting & $499(29.0)$ &
\end{tabular}

a The figures refer to $\mathrm{N}(\%)$

${ }^{\mathrm{b}} \mathrm{p}$ value obtained using chi-squared test

c Median (IQR)

${ }^{d}$ In Nigeria, apart from the formal educational system, a non-formal Arabic and Islamic Educational System operates among the Nigerian Muslims, through Quranic schools

e Only respondents who reported sexual intercourse in the last 12 months were asked these questions

${ }^{f}$ Scored based on the responses to the following five questions: (1) preventing unwanted pregnancies is a benefit of contraception, (2) some contraceptive methods reduce sexually transmitted infections, (3) modern contraception can help with delaying having a first child, (4) modern contraception can help with child spacing and (5) using modern contraception can allow a woman to complete her education, find a better job and have a better life

9 Scored based on the responses to the following four questions: (1) some modern contraception can stop an adolescent woman from ever being pregnant again even after she stops using it, (2) if a modern contraception changes an adolescent woman's menstrual bleeding, it's bad for her health and can harm her womb, (3) some modern contraceptives can make girls permanently fat and (4) girls who use modern contraception sleep with too many men

${ }^{\mathrm{h}}$ Scored based on the responses to the following four questions: (1) felt able to start a conversation with her partner about contraception, (2) felt able to use a method of contraception even if her partner did not want her to, (3) felt able to obtain information on contraception services and products if she needed to and (4) felt able to obtain a contraceptive method if she decided to use one

i DHS definition [43]. Women reporting mistimed or unwanted pregnancies or recent births were considered having unmet need for spacing and for limiting, respectively [43]. In addition, fecund women who wanted children 2 or more years in the future, or were undecided whether/when they wanted a child were regarded as having an unmet need for spacing. Fecund women who wanted no more children were regarded as having an unmet need for limiting [43]. The denominator for the calculation of unmet need is the total of unmarried women aged 15-19 years. The numerator includes only women who were not using contraception at the time of the survey [7]

95\% CI 2.3-4.2). The odds of using MC were significantly higher in women who had never given birth compared with those who had (adjOR 1.5, 95\% CI 1.1-2.1).

\section{Discussion}

Overall, $45 \%$ of sexually active adolescent women in our study reported using MC, a higher proportion than the national prevalence of $22.2 \%$ for sexually active, unmarried 15-19 year olds in the 2018 DHS [7]. This is not surprising given that our sample focused on a region of Nigeria with relatively high income, rate of urbanization, and acceptance of use of MC. Contraceptive use may be more acceptable in Ogun state; among married women of reproductive age, $32.1 \%$ of women in Ogun use any method of contraception, compared to $16.6 \%$ nationally [7].

Available literature documents various beliefs that lead to low uptake of contraception among women of reproductive age, including stigma against premarital sex, unwillingness of parents to discuss contraception with their children, infrequent intercourse, and perception that use of contraception is harmful to health and may hinder a woman's ability to bear children in the future [22, 26-28]. This stigma also results in exclusion of unmarried adolescents from reproductive health surveys, services and strategies. Studies in both Nigeria and Sierra Leone have shown that sexually active unmarried women have less exposure to family planning information than their married counterparts [27].

Despite holding misconceptions, a majority of our survey respondents had good knowledge about contraception. Our results provided some evidence that this knowledge may be associated with contraceptive use. Similar studies with girls in Ghana have shown no association [22, 26], whilst a study in Tanzania showed higher contraceptive uptake associated with increased knowledge [12]. However, there is extensive evidence from Nigeria that misconceptions about contraception have a negative effect on contraceptive uptake [29,30].

Respondents reported low levels of social support for use of $\mathrm{MC}$, from partners and from their mothers. Although social support from partners has been shown as important in married women in Nigeria [31-34], there is limited research on partner influence on unmarried 
Table 2 Contraception use by unmarried sexually active women aged 15-19 years in Ogun, South Western Nigeria $(\%,(95 \% \mathrm{Cl}))$

\begin{tabular}{lll}
\hline Characteristic & Number $(\mathbf{N}=\mathbf{1 8 4 4})^{\mathbf{a}}$ & \% (95\% Cl) \\
\hline Any method & 1165 & $63.2(60.6-65.7)$ \\
Any modern method ${ }^{\mathrm{b}}$ & 836 & $45.3(42.9-47.8)$ \\
Any traditional method & 329 & $17.8(15.9-19.9)$ \\
Not currently using & 572 & $31.0(28.7-33.4)$ \\
Don't know & 8 & $0.43(0.20-0.94)$ \\
No response & 99 & $5.4(4.5-6.5)$ \\
Total & 1844 & 100.0 \\
Method & $\mathrm{N}=1165$ & \\
Modern method & & \\
Female sterilization & 1 & $0.09(0.01-0.61)$ \\
Implant & 8 & $0.69(0.35-1.4)$ \\
IUCD & 1 & $0.09(0.01-0.61)$ \\
Injectables & 5 & $0.43(0.18-1.0)$ \\
Oral contraceptive pill & 26 & $2.2(1.5-3.3)$ \\
Emergency pill & 194 & $16.7(14.6-19.0)$ \\
Male condom & 586 & $50.3(47.4-53.3)$ \\
Female condom & 4 & $0.34(0.13-0.91)$ \\
SDM & 7 & $0.84(0.40-75.8)$ \\
LAM & 4 & $0.34(0.13-0.91)$ \\
Traditional method & & $0.43(0.15-1.2)$ \\
Rhythm method & 5 & $20.7(18.2-23.5)$ \\
Withdrawal & 241 & $3.9(3.0-5.3)$ \\
Drinks salt solution & 46 & $3.2(2.2-4.5)$ \\
Other & 37 & 100.0 \\
Total & 1165 & \\
\hline & & \\
\hline
\end{tabular}

Figures are $\%(95 \% \mathrm{Cl})$

a Unmarried girls who report sexually activity in last 12 months

b Modern methods include female sterilisation, male sterilisation, contraceptive pill (oral contraceptives), IUCD (intrauterine contraceptive devices), injectables

(Depo-Provera), implants (Norplant), female condom, male condom, diaphragm, contraceptive foam and contraceptive jelly, LAM (lactational amenorrhoea method), SDM (standard days method), cycle beads

girls. However, lack of men's support for contraceptive use can be a barrier for women [35], and some men believe that their partner's contraceptive use could lead to promiscuity or infidelity [36, 37]. This highlights the importance of including men in conversations about contraceptive use. Sexual behaviour in unmarried adolescents is taboo for cultural and religious reasons; parents who do not approve of their daughters engaging in sexual activity are not likely to support their contraceptive use. Furthermore, it is often taboo for parents to discuss sexual activity with their children. This limits the ability of girls to learn about MC through interpersonal family channels.

Seventy percent of the respondents using a MC method reported using condoms, with the next most common method being emergency contraception (23\%). These findings are in line with the most recent Nigeria DHS, where condoms made up $75 \%$ of modern contraceptive use among unmarried sexually active girls [7]. A study conducted in the Ashanti region of Ghana [26] also revealed that condoms (33.3\%) were the most used form of contraceptive among sexually active female adolescents. We believe that the common use of condoms, a short-term method of contraception, may be because they are presumed to have no side effects and are more easily available and accessible from providers [38]. This may be particularly important in this population, where although $45 \%$ of sexually active girls used contraception, only $39 \%$ knew of a place they felt comfortable accessing it - this may limit them to seeking only the most accessible form of contraception. Infrequent sexual activity may also be a reason for a preference for short-term methods. Short-term methods also have little risk of being discovered by parents-relevant for this population where perceived parental approval of contraceptive use is very low.

Many of this survey's respondents reported using traditional contraceptive methods such as withdrawal or drinking salt solutions (17.8\%). The use of traditional contraception is much higher in Nigeria as compared to a similar study in the same demographic group in Tanzania, where only $2 \%$ of unmarried adolescent girls aged 15-19 were using a traditional contraceptive method [12]. Although the reasons for this are not clear, data collected from women of reproductive age in Nigeria's most recent DHS show that women with higher education levels, in higher income quintiles, and in urban areas are more likely to use MC [7]. This implies that mistrust in $\mathrm{MC}$ or barriers to accessing MC may be an important factor. A large proportion of unmarried girls who reported having ever been pregnant also reported that they had never given birth which suggests that some of the women interviewed may have terminated their pregnancies emphasising the high unmet need in this population.

In contrast to the high rates of short-term contraceptive use, there is a large global emphasis on encouraging long-acting reversible contraceptives (LARCs). These methods have advantages - they are female-controlledbut they also have disadvantages - they may face significant access barriers, can be more likely to cause side effects, and do not protect against sexually transmitted infections. Girls who have sex infrequently, such as those in our survey population, may also feel that the infrequent protection offered by condoms is sufficient; they may also feel that the risk of side effects from LARCs is too high given their infrequent sexual activity.

Injectable contraceptive use was very low in this population, with less than $1 \%$ of sexually active girls reporting use of this method. Although adolescents in sub-Saharan 
Table 3 Factors associated with modern contraception use among unmarried sexually active women aged 15-19 years in Ogun, South Western Nigeria, $(\mathbf{N}=1737)$

\begin{tabular}{|c|c|c|c|c|c|c|}
\hline Exposure category & No & Prevalence, $n(\%)$ & Unadjusted OR $(95 \% \mathrm{Cl})$ & p value & Adjusted OR (95\% Cl) & $p$ value \\
\hline \multicolumn{7}{|l|}{ Sociodemographic factors } \\
\hline \multicolumn{7}{|l|}{ Age (years) } \\
\hline 15 & 60 & $20(33.3)$ & & & & \\
\hline 16 & 113 & $48(42.5)$ & & & & \\
\hline 17 & 221 & $94(42.5)$ & & & & \\
\hline 18 & 522 & $285(54.6)$ & & & & \\
\hline 19 & 821 & $389(47.4)$ & & & & \\
\hline Per year increase & & & $1.10(1.00-1.20)$ & 0.04 & & \\
\hline \multicolumn{7}{|l|}{ Religion } \\
\hline Catholic & 34 & $18(52.9)$ & 1 & & & \\
\hline Protestant/other christian & 1119 & $553(49.4)$ & $0.87(0.47-1.6)$ & & & \\
\hline Muslim & 578 & $264(45.7)$ & $0.75(0.40-1.4)$ & & & \\
\hline Traditional & 6 & $1(16.7)$ & $0.18(0.02-1.7)$ & 0.22 & & \\
\hline \multicolumn{7}{|c|}{ Highest education level achieved ${ }^{\mathrm{a}}$} \\
\hline No education/primary & 115 & $32(27.8)$ & 1 & & 1 & \\
\hline Secondary & 1459 & $698(47.8)$ & $2.4(1.6-3.6)$ & & $2.4(1.5-3.6)$ & \\
\hline Higher education & 163 & $106(65.0)$ & $4.8(2.8-8.2)$ & $<0.001$ & $4.6(2.7-8.0)$ & $<0.001$ \\
\hline \multicolumn{7}{|l|}{ Currently in education $^{a}$} \\
\hline Yes & 549 & $284(51.7)$ & 1 & & 1 & \\
\hline No & 1188 & $552(46.5)$ & $0.81(0.66-0.99)$ & 0.04 & $0.73(0.59-0.90)$ & 0.003 \\
\hline \multicolumn{7}{|l|}{ Type of residence ${ }^{a}$} \\
\hline Urban & 630 & $334(53.0)$ & 1 & & 1 & \\
\hline Semi-urban & 719 & $349(48.5)$ & $0.84(0.67-1.0)$ & & $0.84(0.67-1.0)$ & \\
\hline Rural & 388 & $153(39.4)$ & $0.58(0.44-0.76)$ & $<0.001$ & $0.59(0.45-0.77)$ & $<0.001$ \\
\hline \multicolumn{7}{|l|}{ Socioeconomic level ${ }^{a}$} \\
\hline Lowest to middle quintile & 66 & $18(27.3)$ & 1 & & 1 & \\
\hline Second highest quintile & 334 & $144(43.1)$ & $2.0(1.1-3.8)$ & & $2.0(1.1-3.8)$ & \\
\hline Highest quintile & 1301 & $664(51.0)$ & $2.8(1.5-5.1)$ & $<0.001$ & $2.7(1.5-5.0)$ & $<0.001$ \\
\hline \multicolumn{7}{|c|}{ Exposure to information about contraception } \\
\hline \multicolumn{7}{|c|}{ Heard about contraception in the media in last 12 months? ${ }^{b}$} \\
\hline Yes & 380 & $227(59.7)$ & 1 & & 1 & \\
\hline No & 1197 & $577(48.2)$ & $0.63(0.50-0.79)$ & $<0.001$ & $0.65(0.51-0.82)$ & $<0.001$ \\
\hline \multicolumn{7}{|c|}{ Heard about contraception from health sector sources in last 12 months? ${ }^{b}$} \\
\hline Yes & 394 & $248(62.9)$ & 1 & & 1 & \\
\hline No & 1183 & $556(47.0)$ & $0.52(0.41-0.67)$ & $<0.001$ & $0.53(0.42-0.68)$ & $<0.001$ \\
\hline \multicolumn{7}{|c|}{ Heard about contraception from interpersonal sources in last 12 months? ${ }^{b}$} \\
\hline Yes & 946 & $496(52.4)$ & 1 & & 1 & \\
\hline No & 631 & $308(48.8)$ & $0.87(0.70-1.1)$ & 0.18 & $0.88(0.71-1.1)$ & 0.25 \\
\hline \multicolumn{7}{|c|}{ Knows a place where or a person from whom she would feel comfortable accessing contraception? ${ }^{\mathrm{b}}$} \\
\hline Yes & 639 & $369(57.8)$ & 1 & & 1 & \\
\hline No & 870 & $396(45.5)$ & $0.61(0.50-0.75)$ & & $0.65(0.53-0.81)$ & \\
\hline Don't know & 63 & $35(55.7)$ & $0.91(0.54-1.6)$ & $<0.001$ & $0.95(0.55-1.6)$ & $<0.001$ \\
\hline \multicolumn{7}{|l|}{ Social networks } \\
\hline \multicolumn{7}{|c|}{ Perception that partner supports her using contraception ${ }^{b}$} \\
\hline Yes & 1018 & $643(63.2)$ & 1 & & 1 & \\
\hline No & 325 & $101(31.1)$ & $0.26(0.20-0.34)$ & & $0.27(0.20-0.35)$ & \\
\hline Don't know & 193 & $44(22.8)$ & $0.17(0.12-0.25)$ & $<0.001$ & $0.17(0.12-0.25)$ & $<0.001$ \\
\hline
\end{tabular}


Table 3 (continued)

\begin{tabular}{|c|c|c|c|c|c|c|}
\hline Exposure category & No & Prevalence, $n(\%)$ & Unadjusted OR $(95 \% \mathrm{Cl})$ & p value & Adjusted OR (95\% Cl) & p value \\
\hline \multicolumn{7}{|c|}{ Perception that mother supports her using contraception ${ }^{b}$} \\
\hline Yes & 358 & $195(54.5)$ & 1 & & 1 & \\
\hline No & 710 & $364(51.3)$ & $0.88(0.69-1.1)$ & & $0.87(0.67-1.1)$ & \\
\hline Don't know & 341 & $163(47.8)$ & $0.77(0.57-1.0)$ & 0.19 & $0.76(0.56-1.0)$ & 0.20 \\
\hline \multicolumn{7}{|c|}{ Perception that friends supports her using contraception ${ }^{b}$} \\
\hline Yes & 892 & $519(58.2)$ & 1 & & 1 & \\
\hline No & 333 & $43.2(144)$ & $0.55(0.43-0.70)$ & & $0.54(0.42-0.70)$ & \\
\hline Don't know & 352 & $40.1(141)$ & $0.48(0.37-0.62)$ & $<0.001$ & $0.48(0.37-0.63)$ & $<0.001$ \\
\hline \multicolumn{7}{|c|}{ Individual knowledge, attitudes and behaviours } \\
\hline \multicolumn{7}{|c|}{ Knowledge about contraception ${ }^{\mathrm{b}}$} \\
\hline $0-1$ & 58 & $22(37.9)$ & 1 & & 1 & \\
\hline $2-3$ & 316 & $148(46.8)$ & $1.4(0.81-2.6)$ & & $1.4(0.74-2.5)$ & \\
\hline $4-5$ & 1203 & $634(52.7)$ & $1.8(1.0-3.2)$ & 0.03 & $1.7(0.95-3.1)$ & 0.08 \\
\hline \multicolumn{7}{|c|}{ Misconceptions about contraception } \\
\hline $0-1$ & 494 & $251(50.8)$ & 1 & & & \\
\hline $2-3$ & 813 & $422(51.9)$ & $(0.83-1.3)$ & & & \\
\hline 4 & 270 & $131(48.5)$ & $0.91(0.66-1.3)$ & 0.64 & & \\
\hline \multicolumn{7}{|c|}{ Self-efficacy for contraception ${ }^{b}$} \\
\hline $0-1$ & 277 & $90(32.5)$ & 1 & & 1 & \\
\hline $2-3$ & 608 & $281(46.2)$ & $1.8(1.3-2.4)$ & & $1.7(1.2-2.3)$ & \\
\hline 4 & 743 & $460(61.9)$ & $3.4(2.5-4.6)$ & $<0.001$ & $3.1(2.3-4.2)$ & $<0.001$ \\
\hline \multicolumn{7}{|l|}{ Ever been pregnant } \\
\hline Yes & 385 & 191 (49.6) & 1 & & & \\
\hline No/don't know & 1352 & $645(47.7)$ & $0.93(0.75-1.1)$ & 0.48 & & \\
\hline \multicolumn{7}{|l|}{ Ever given birth ${ }^{b}$} \\
\hline Yes & 165 & $61(37.0)$ & 1 & & 1 & \\
\hline No & 1572 & 775 (49.3) & $1.7(1.2-2.3)$ & 0.002 & $1.5(1.1-2.1)$ & 0.01 \\
\hline
\end{tabular}

Africa have been reported to prefer injectable contraceptive methods, these methods are less popular in Nigeria [39]. The 2018 DHS reports that 3\% of married women aged 15-49 and 2\% of unmarried women aged 15-49 currently using a contraceptive method are using an injectable method. Although injectables are more commonly used in Nigeria's South West, they are only used by $0.6 \%$ of women aged $15-49$ in Ogun state.

\section{Strengths}

This survey targeted sexually active unmarried adolescents aged 15-19, a group rarely covered in family planning literature despite the unique barriers they face in accessing contraception. Most of the data available on determinants of contraceptive use are based on samples of married adult women [40] or are representative of all women aged 15-49 [41]. Even where girls are included, data is often presented for the 15-24 year old age group, and absolute numbers of adolescent women surveyed are quite small. For example, the 2018 Nigeria DHS surveyed only 310 sexually active unmarried women aged 15-19 across the entire nation [7].

This survey targeted a large number of unmarried adolescent girls in Ogun state, Nigeria. The sampling method makes this data largely generalizable for the LGAs where the study was conducted. Ogun state is a large, highly populated and largely urban state with similar cultural context to other neighbouring states; this study could therefore inform programming for a large population of adolescent girls living in urban areas in Nigeria. Furthermore, these findings could be used to inform future 
research and programming in urban adolescents across Africa as the continent's urban populations continue to increase [42].

\section{Limitations}

The findings of this survey cannot describe causality of use of MC, a weakness of all cross-sectional analyses. It is unclear, for example, whether women use $\mathrm{MC}$ because they are knowledgeable about it, or women are knowledgeable about MC because they are using it. Similarly, it is not clear that reaching higher education makes women more likely to use $\mathrm{MC}$ - women using $\mathrm{MC}$ may be more likely to reach higher education because they are not shut out of the school system due to early pregnancy.

The data collection relied on self-reporting of sensitive information. Despite the best efforts of the research team to minimize risks there is potential misreporting of information from survey participants [7].

This survey reached only girls residing in households at the time of interview; the non-response rate was largely due to girls being away at school, which could limit generalizability of the results to some extent.

Finally, the data and conclusions may be affected by unmeasured confounding, and conclusions may not be fully representative due to chance.

\section{Recommendations}

Reproductive health programming tailored to the needs of unmarried sexually active adolescent women in South Western Nigeria should seek to increase access to modern contraceptives and promote accurate information about traditional methods with no known efficacy, e.g. drinking salt solutions.

Emphasis on increasing social acceptance of contraceptive use, especially by parents, should also be a priority. Finally, two of the more common contraceptive methods women reported using-condoms and withdrawal-rely on male control. Programmes promoting contraceptive use should also incorporate female-controlled options for birth control and should also engage men as key participants in reproductive health.

Programmes aiming to increase voluntary uptake of $\mathrm{MC}$ among unmarried adolescent girls should also incorporate activities to combat the stigma of girls accessing contraception and should seek to identify and remove barriers that young women face in accessing modern methods.

\section{Conclusions}

This study demonstrates that unmarried adolescent women in South West Nigeria are sexually active and have unmet need for family planning. Although most unmarried girls have heard of modern contraception, the majority do not know a place they would feel comfortable accessing it. Programming that seeks to increase unmarried adolescents' access to modern contraception should promote accurate information about modern contraception, provide multiple options including long-term and short-term contraceptive options, and should engage male partners of girls as well. Supporting girls in delaying childbearing until they desire a child would not only reduce the risks of early pregnancy but would also support girls in completing school and achieving their goals for adult life.

\section{Abbreviations \\ A360: Adolescent 360; LGA: Local government areas; MC: Modern contracep- tion; SSA: Sub-Saharan Africa; SDG: Sustainable Development Goals; FP2020: Family planning 2020; EA: Enumeration area; DHS: Demographic and Health Survey; CAPI: Computer-Assisted Personal Interviewing; mCPR: Modern Contraceptive Prevalence Rate; LARC: Long-acting reversible contraceptives; IUCD: Intrauterine contraceptive device; SDM: Standard days method; LAM: Lactational amenorrhoea method.}

\section{Acknowledgements}

We would like to thank all study participants for their participation and the A360 baseline study team for their dedicated work during data collection. We also thank Itad as the lead organisation responsible for the overall A360 evaluation. Avenir Health as a partner in the overall A360 evaluation. PSI Headquarters and SFH Nigeria for their support with site selection and engagement in conversation regarding the design. We want to thank the Local Government Area (Ado-Odo Ota and Sagamu) Authorities of Ogun State for granting the permission to conduct the survey in the different communities.

\section{Authors' contributions}

$\mathrm{EC}, \mathrm{YO}, \mathrm{CJ} \mathrm{A}$ and $\mathrm{AMD}$ were involved in conception and study design. EC and CJA were involved in drafting of the manuscript. YO and AMD were involved in critical revision of the manuscript for important intellectual content. All the authors were involved in final approval of the manuscript and decision to submit the manuscript for publication. All authors read and approved the final manuscript.

\section{Funding}

This evaluation was funded by The Bill \& Melinda Gates Foundation, Seattle, WA (Investment ID: INV-009910/OPP1134172) and the Children's Investment Fund Foundation, London, UK. This funding supported the study design and data collection. Funding was not given for the analysis and interpretation of the data for this paper, nor for the preparation of the manuscript. However, the Bill \& Melinda Gates Foundation has funded the publication fees for the manuscript.

\section{Availability of data and materials}

The datasets used during the current study are available from the corresponding author on reasonable request.

\section{Ethics approval and consent to participate}

Participants voluntarily provided verbal informed consent. A waiver of written consent was granted given the sensitive nature of the topics discussed. Women aged 15-17 years provided verbal assent and verbal informed consent was also sought from her parent/guardian. The study protocol was approved by the National Health Research Ethics Committee of Nigeria (Ref: NHREC/01/01/2007-25/05/2017) and the London School of Hygiene and Tropical Medicine Ethics Committee (Ref: 14145).

\section{Consent for publication}

Not applicable.

\section{Competing interests}

The authors declare that they have no competing interests. 


\section{Author details}

${ }^{1}$ Binomial Optimus Limited, Blue Hill, PLOT 538 Natasha Akpoti Street Kado, Abuja, FCT, Nigeria. ${ }^{2}$ Imperial College London, School of Public Health, St Mary's Hospital, Norfolk Place, London W2 1PG, UK. ${ }^{3}$ MRC International Statistics and Epidemiology Group, London School of Hygiene and Tropical Medicine, Keppel St, Bloomsbury, London WC1E 7HT, UK.

Received: 30 June 2020 Accepted: 9 December 2020

Published online: 06 January 2021

\section{References}

1. Blackstone SR, Nwaozuru U, Iwelunmor J. Factors influencing contraceptive use in Sub-Saharan Africa: a systematic review. Int Q Community Health Educ. 2017;37(2):79-91. https://doi.org/10.1177/0272684X16 685254 (Epub 2017 Jan 5).

2. Nalwadda G, Mirembe F, Byamugisha J, Faxelid E. Persistent high fertility in Uganda: young people recount obstacles and enabling factors to use of contraceptives. BMC Public Health. 2010;10:530. https://doi. org/10.1186/471-2458-10-530.

3. Bearinger LH, Sieving RE, Ferguson J, Sharma V. Global perspectives on the sexual and reproductive health of adolescents: patterns, prevention, and potential. Lancet. 2007;369(9568):1220-31. https://doi.org/10.1016/ S0140-6736(07)60367-5

4. The UN 2030 agenda for sustainable development New York: United Nations. 2015. https://www.un.org/sustainabledevelopment/devel opment-agenda/. Accessed 09 Mar 2018.

5. French RS, Geary R, Jones K, Glasier A, Mercer CH, Datta J, et al. Where do women and men in Britain obtain contraception? Findings from the third National Survey of Sexual Attitudes and Lifestyles (Natsal-3). BMJ Sex Reprod Health. 2018;44(1):16.

6. Daniels K, Abma JC. Current contraceptive status among women aged 15-49: United States, 2017-2019. NCHS Data Brief No 388. 2020.

7. The_DHS_Program. 2018 Nigeria Demographic and Health Survey. https ://dhsprogram.com/publications/publication-fr359-dhs-final-repor ts.cfm?cssearch $=51012 \_1$.

8. World Health Organization. The World Health Organisation guidelines on preventing early pregnancy and poor reproductive outcomes among adolescents in developing countries. Geneva: World Health Organization; 2011.

9. Conde-Agudelo A, Belizan JM, Lammers C. Maternal-perinatal morbidity and mortality associated with adolescent pregnancy in Latin America: cross-sectional study. Am J Obstet Gynecol. 2005;192(2):342-9. https:// doi.org/10.1016/j.ajog.2004.10.593.

10. Wodon QT, Male C, Nayihouba KA, Onagoruwa AO, Savadogo A, Yedan A, et al. Economic impacts of child marriage: global synthesis report. Washington, D. C: World Bank Group; 2017.

11. de Vargas Nunes Coll C, Ewerling F, Hellwig F, de Barros AJD. Contraception in adolescence: the influence of parity and marital status on contraceptive use in 73 low-and middle-income countries. Reprod Health. 2019;16(1):21. https://doi.org/10.1186/s12978-019-0686-9.

12. Nsanya MK, Atchison CJ, Bottomley C, Doyle AM, Kapiga SH. Modern contraceptive use among sexually active women aged 15-19 years in North-Western Tanzania: results from the Adolescent 360 (A360) baseline survey. BMJ Open. 2019;9(8):e030485. https://doi.org/10.1136/bmjop en-2019-.

13. Yakubu I, Salisu WJ. Determinants of adolescent pregnancy in sub-Saharan Africa: a systematic review. Reprod Health. 2018;15(1):15.

14. Kassa GM, Arowojolu AO, Odukogbe AA, Yalew AW. Prevalence and determinants of adolescent pregnancy in Africa: a systematic review and meta-analysis. Reprod Health. 2018;15(1):195.

15. Udegbe BI, Fayehun F, Isiugo-Abanihe UC, Nwagwu W, Isiugo-Abanihe I, Nwokocha E. Evaluation of the implementation of family life and HIV education programme in Nigeria. Afr J Reprod Health. 2015;19(2):79-93.

16. Nigerian Educational Research and Development Council. National family life and HIV education curriculum for junior secondary school in Nigeria. Abuja: Nigerian Educational Research and Development Council; 2003.

17. Wood S, Rogow D. Can sexuality education advance gender equality and strengthen education overall? Learning from Nigeria's family life and HIV education program. New York: International Women's Health Coalition; 2015.

18. Nigeria: Act No. 26 of 2003, Child's Rights Act, 2003 Nigeria. 2003. https:// www.refworld.org/docid/5568201f4.html. Accessed 15 Oct 2020

19. Singh J, Jogee F. Age of Consent: legal, ethical, cultura and social review-Nigeria Country Report 2018.

20. Schwandt HM, Speizer IS, Corroon M. Contraceptive service provider imposed restrictions to contraceptive access in urban Nigeria. BMC Health Serv Res. 2017;17(1):268.

21. Atchison CJ, Mulhern E, Kapiga S, Nsanya MK, Crawford EE, Mussa M, et al. Evaluating the impact of an intervention to increase uptake of modern contraceptives among adolescent girls (15-19 years) in Nigeria, Ethiopia and Tanzania: the Adolescents 360 quasi-experimental study protocol. BMJ Open. 2018;8(5):e021834. https://doi.org/10.1136/bmjopen-2018-.

22. Enuameh Y, Nettey E, Mahama E, Tawiah C, Boamah E, Sulemana A, et al. Family planning needs of adolescents in predominantly rural communities in the Central Part of Ghana. Open J Prev Med. 2015;05:269-79.

23. The_DHS_Program. 2013 Nigeria demographic and health survey. http:// dhsprogram.com/publications/publication-fr293-dhs-final-reports.cfm.

24. World_Health_Organization. World Health Organisation family planning fact sheet. https://www.who.int/news-room/fact-sheets/detail/famil y-planning-contraception. Accessed 9 Mar 2018.

25. Jones $\mathrm{JH}$, Salathé $\mathrm{M}$. Early assessment of anxiety and behavioral response to novel swine-origin influenza A(H1N1). PLoS ONE. 2009;4(12):e8032-e.

26. Agyemang J, Newton S, Nkrumah I, Tsoka-Gwegweni JM, Cumber SN. Contraceptive use and associated factors among sexually active female adolescents in Atwima Kwanwoma District, Ashanti region-Ghana. Pan Afr Med J. 2019;32:182. https://doi.org/10.11604/pamj.2019.32.182.5344 (eCollection 2019)

27. Chandra-Mouli V, McCarraher DR, Phillips SJ, Williamson NE, Hainsworth G. Contraception for adolescents in low and middle income countries: needs, barriers, and access. Reprod Health. 2014;11(1):1. https://doi. org/10.1186/742-4755-11-1.

28. Sedgh G, Ashford L, Hussain R. Unmet need for contraception in developing countries: examining Women's reasons for not using a method. New York: Guttmacher Institute; 2016.

29. Akamike IC, Okedo-Alex IN, Eze II, Ezeanosike OB, Uneke CJ. Why does uptake of family planning services remain sub-optimal among Nigerian women? A systematic review of challenges and implications for policy. Contracept Reprod Med. 2020;5:30.

30. Adeyemi AS, Olugbenga-Bello Al, Adeoye OA, Salawu MO, Aderinoye AA, Agbaje MA. Contraceptive prevalence and determinants among women of reproductive age group in Ogbomoso, Oyo State, Nigeria. Open Access J Contracept. 2016;7:33-41.

31. Shahjahan M, Mumu SJ, Afroz A, Chowdhury HA, Kabir R, Ahmed K. Determinants of male participation in reproductive healthcare services: a cross-sectional study. Reprod Health. 2013;10:27. https://doi. org/10.1186/742-4755-10-27.

32. Kraft JM, Harvey SM, Hatfield-Timajchy K, Beckman L, Farr SL, Jamieson DJ, et al. Pregnancy motivations and contraceptive use: hers, his, or theirs? Womens Health Issues. 2010;20(4):234-41. https://doi.org/10.1016/j. whi.2010.03.008.

33. Ezeanolue EE, Iwelunmor J, Asaolu I, Obiefune MC, Ezeanolue CO, Osuji A, et al. Impact of male partner's awareness and support for contraceptives on female intent to use contraceptives in southeast Nigeria. BMC Public Health. 2015;15:879. https://doi.org/10.1186/s12889-015-2216-1.

34. Nwachukwu I, Obasi OO. Use of modern birth control methods among rural communities in Imo State, Nigeria. Afr J Reprod Health. 2008;12(1):101-8.

35. Aransiola JO, Akinyemi Al, Fatusi AO. Women's perceptions and reflections of male partners and couple dynamics in family planning adoption in selected urban slums in Nigeria: a qualitative exploration. BMC Public Health. 2014;14:869. https://doi.org/10.1186/471-2458-14-869.

36. Kabagenyi A, Jennings $L$, Reid A, Nalwadda G, Ntozi J, Atuyambe L. Barriers to male involvement in contraceptive uptake and reproductive health services: a qualitative study of men and women's perceptions in two rural districts in Uganda. Reprod Health. 2014;11(1):21. https://doi. org/10.1186/742-4755-11-21.

37. Marchi NM, de Alvarenga AT, Osis MJ, Bahamondes L. Contraceptive methods with male participation: a perspective of 
Brazilian couples. Int Nurs Rev. 2008;55(1):103-9. https://doi.org/10.111 1/j.466-7657.2007.00572.x.

38. Nmadu AG, Mohammed S, Usman NO. Barriers to adolescents' access and utilisation of reproductive health services in a community in northwestern Nigeria: a qualitative exploratory study in primary care. Afr J Prim Health Care Fam Med. 2020;12(1):e1-5.

39. McCurdy RJ, Schnatz PF, Weinbaum PJ, Zhu J. Contraceptive use in adolescents in Sub-Saharan Africa: evidence from demographic and health surveys. Conn Med. 2014:78(5):261-72.

40. Akinyemi A, Adedini S, Hounton S, Akinlo A, Adedeji O, Adonri O, et al. Contraceptive use and distribution of high-risk births in Nigeria: a sub-national analysis. Glob Health Action. 2015;8:29745. https://doi. org/10.3402/gha.v8.29745 (eCollection 2015).
41. Okigbo CC, Speizer IS, Domino ME, Curtis SL, Halpern CT, Fotso JC. Gender norms and modern contraceptive use in urban Nigeria: a multilevel longitudinal study. BMC Womens Health. 2018;18(1):178. https://doi. org/10.1186/s12905-018-0664-3.

42. UN Department of Economic and Social Affairs (UN DESA). 2018 revision of world urbanization prospects. New York; 2019.

43. Bradley SE, Casterline JB. Understanding unmet need: history, theory, and measurement. Stud Fam Plann. 2014;45(2):123-50. https://doi.org/10.111 1/j.728-4465.2014.00381.x.

\section{Publisher's Note}

Springer Nature remains neutral with regard to jurisdictional claims in published maps and institutional affiliations.
Ready to submit your research? Choose BMC and benefit from:

- fast, convenient online submission

- thorough peer review by experienced researchers in your field

- rapid publication on acceptance

- support for research data, including large and complex data types

- gold Open Access which fosters wider collaboration and increased citations

- maximum visibility for your research: over $100 \mathrm{M}$ website views per year

At BMC, research is always in progress.

Learn more biomedcentral.com/submissions 